\title{
Mitral commissural prolapse
}

EVA PAPADIMITRAKI ${ }^{1}$, Alexandros Patrianakos ${ }^{2}$, Antonis Pitsis ${ }^{3}$, Maria Marketou ${ }^{2}$, Aggeliki Zacharaki ${ }^{1}$, and Fragiskos Parthenakis ${ }^{1}$

${ }^{1}$ University General Hospital of Heraklion Medical Service

${ }^{2}$ HERAKLION UNIVERSITY HOSPITAL

${ }^{3}$ St.Luke's Hospital

November 28, 2020

\begin{abstract}
Mitral commissural prolapse or flail, either isolated or combined with more extensive degenerative valve disease imposes several challenges both on its diagnosis and management whilst being a risk factor for valve reoperation after mitral valve repair. Accurate identification of the prolapsing segment is often not feasible with transthoracic 2D echocardiography, with transesophageal 3D imaging then required for correct diagnosis and surgical planning. Various surgical techniques employed alone or in combination, have yielded good results in the repair of commissural prolapse. Herein, we analyze the specific characteristics of commissural disease focusing our attention on 2D and 3D echocardiographic findings and we briefly comment on techniques employed for surgical correction of the disease.
\end{abstract}

\section{Hosted file}

Mitral commissural prolapse ECHOCARDIOGRAPHY.pdf available at https://authorea.com/users/ 379527/articles/495728-mitral-commissural-prolapse 

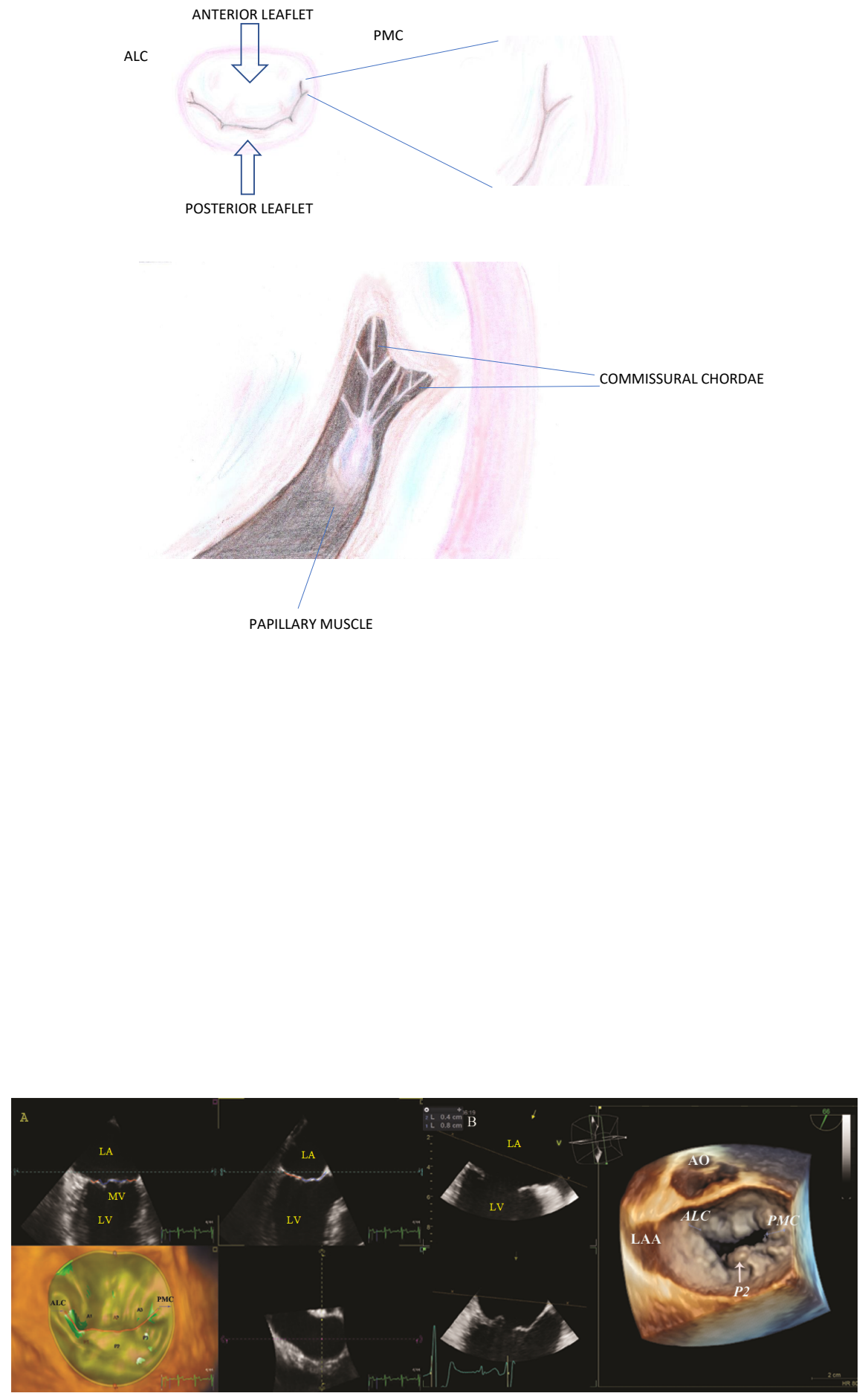

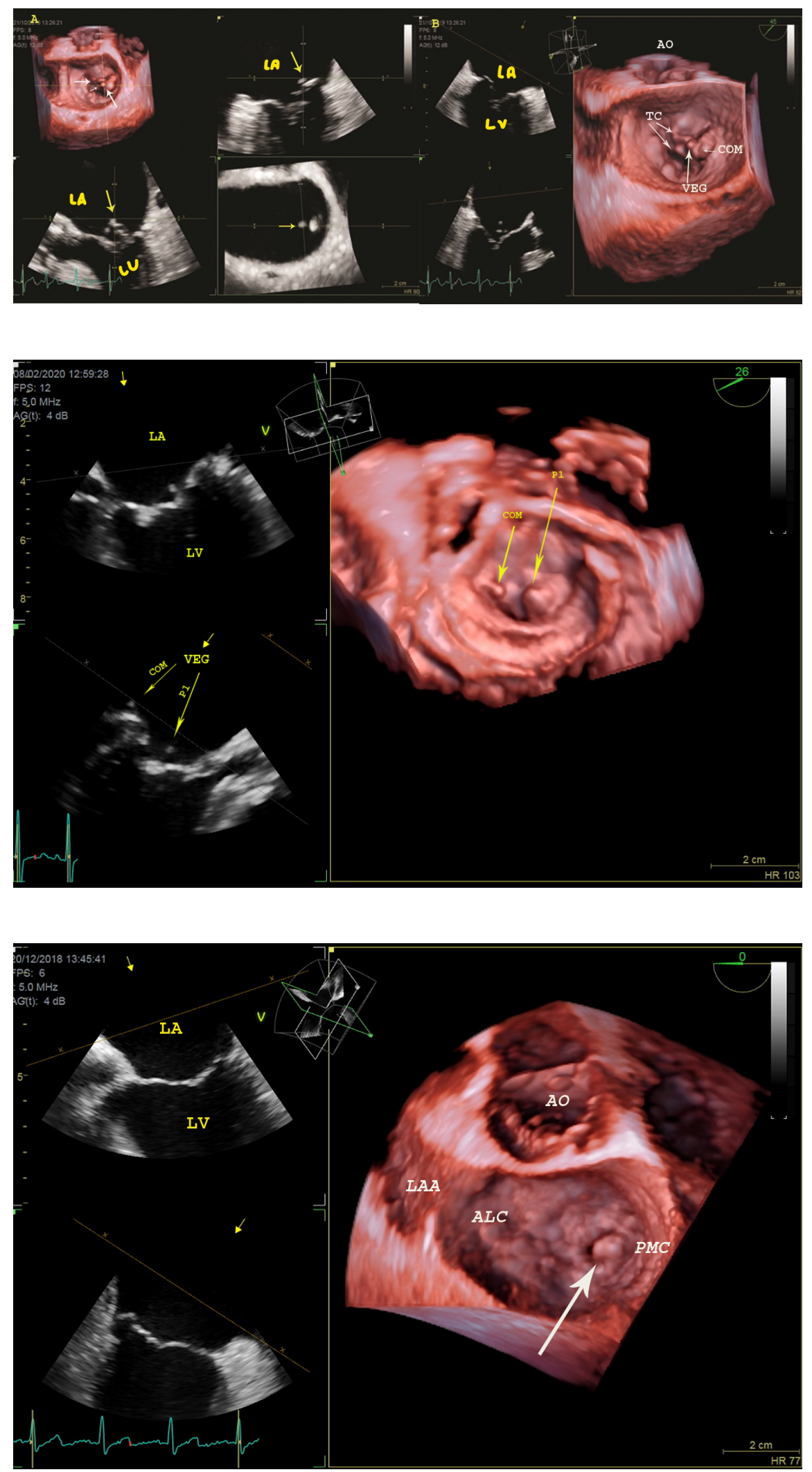

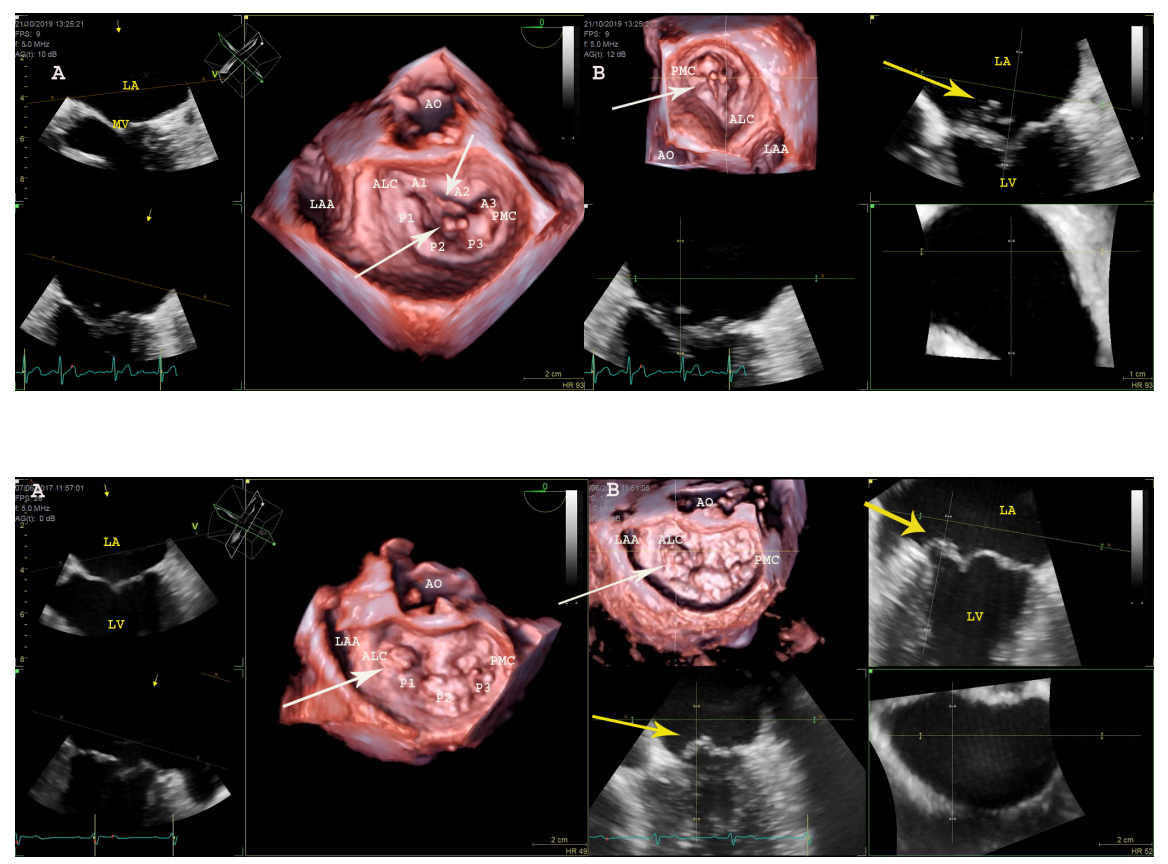

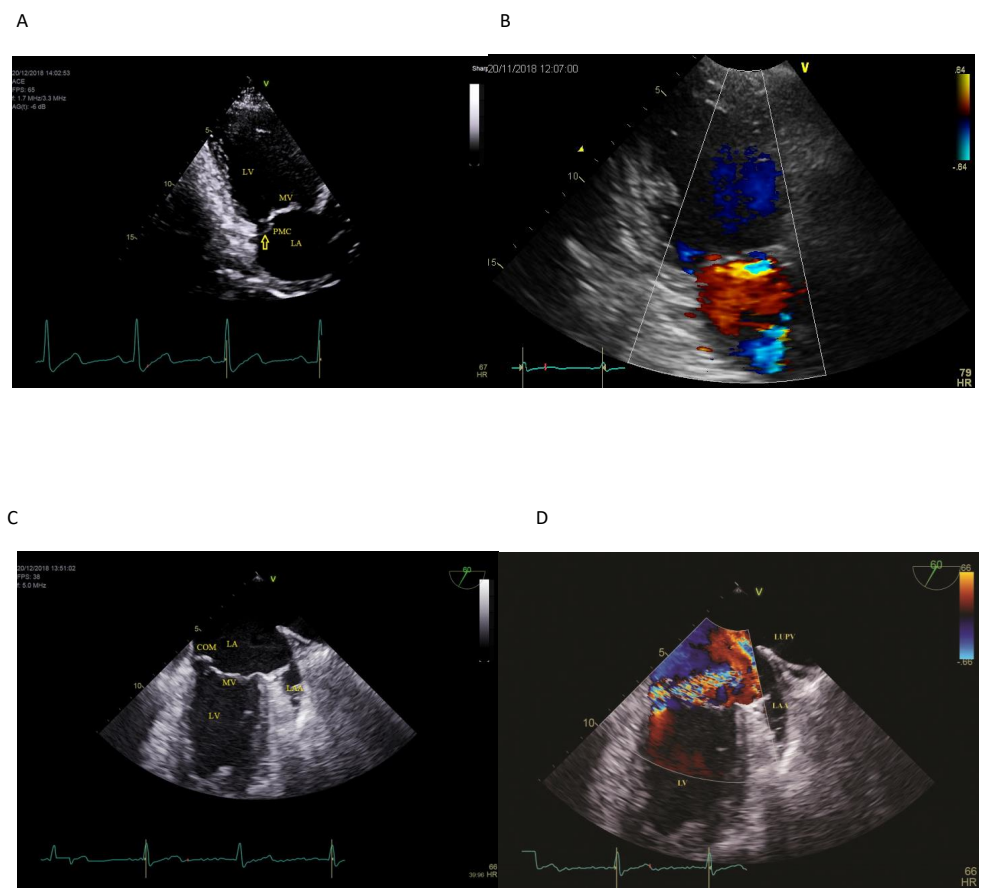


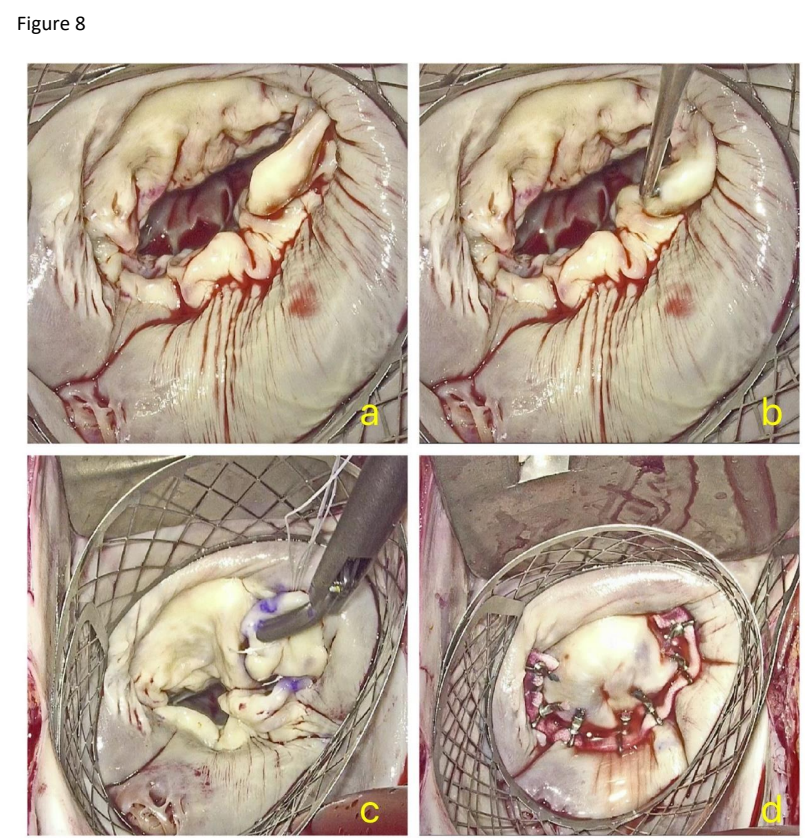

